\title{
Educação, diálogo e prática da liberdade em Paulo Freire: revisitando a pedagogia do oprimido
}

\author{
Educación, diálogo y práctica de la libertad en Paulo Freire: revisando la pedagogía \\ de los oprimidos
}

\section{Education, dialogue and practice of freedom in Paulo Freire: reviewing the pedagogy of the oppressed}

\author{
Thiago Ingrassia Pereira* \\ Jerônimo Sartori*
}

\section{Resumo}

O objeto deste estudo é a análise da obra Pedagogia do Oprimido em uma perspectiva crítica, procurando refletir acerca das limitações e potencialidades da educação e do diálogo na sua relação com a prática da liberdade. $\mathrm{O}$ foco está na compreensão de como a obra contribui para problematizar as críticas e dialogar com a função transformadora da educação, tendo em vista a perspectiva do que se explicita no livro. Examina-se como a proposta freireana de educação pode pensar e efetivar ações perpassadas pelo diálogo e que resultem na formação de sujeitos capazes de agir no horizonte da prática da liberdade. A reflexão é construída pelo olhar de um "quefazer" crítico-reflexivo, pois a formação do sujeito é tratada como algo dinâmico, que se (re)constrói no movimento do processo pedagógico. O itinerário metodológico do estudo, que é eminentemente bibliográfico, toma, especialmente, o capítulo 3, "A dialogicidade, essência da educação como prática da liberdade", considerando aspectos facilitadores, os desafios e as incompletudes, tanto dos sujeitos como dos processos formativos. O texto aponta os fundamentos da pedagogia freireana que embasam o diálogo como princípio que fortalece e (re)dimensiona a prática da liberdade que se configura nas possibilidades de libertação dos sujeitos.

Palavras-chave: Pedagogia freireana. Educação. Diálogo. Prática da liberdade.

Recebido em 24/04/2020 - Aprovado em 28/09/2020

http://dx.doi.org/10.5335/rep.v27i3.12368

Pós-Doutor em Educação (2018) pela Universidade de Lisboa. Mestre (2007) e Doutor (2014) em Educação pela Universidade Federal do Rio Grande do Sul. Sociólogo. Professor da área de Fundamentos da Educação e do PPGPE e PPGICH da UFFS, Campus Erechim. Orcid: https://orcid.org/0000-0002-5558-7836. E-mail: thiago.ingrassia@gmail.com

** Pós-Doutorado em Educação na Universidade de Passo Fundo (UPF). Doutor em Educação pela Universidade Federal do Rio Grande do Sul. Professor do Programa de Pós-Graduação Profissional em Educação (PPGPE) da Universidade Federal da Fronteira Sul (UFFS), Campus Erechim. Orcid: http://orcid.org/0000-0001-5099-1138. E-mail: jetori55@yahoo.com.br 


\section{Resumen}

El objetivo de este estudio es el análisis de la obra Pedagogía de los oprimidos en una perspectiva crítica, buscando reflexionar sobre las limitaciones y el potencial de la educación y el diálogo en su relación con la práctica de la libertad. El objetivo es entender cómo el trabajo contribuye a problematizar las críticas y el diálogo con la función transformadora de la educación, en vista de la perspectiva de lo que se explica en el libro. Examina cómo la propuesta freireana para la educación puede pensar y llevar a cabo acciones permeadas por el diálogo y que resultan en la formación de sujetos capaces de actuar dentro del alcance de la práctica de la libertad. La reflexión se construye mirando un "qué hacer" crítico-reflexivo, ya que la formación del sujeto se trata como algo dinámico que (re) construye en el movimiento del proceso pedagógico. El itinerario metodológico del estudio, que es eminentemente bibliográfico, toma, en particular, el capítulo 3 "La dialógica, la esencia de la educación como práctica de la libertad", considerando aspectos facilitadores, desafíos e incompletos, tanto de las asignaturas como de los procesos de capacitación. El texto señala los fundamentos de la pedagogía de Freire que basan el diálogo como un principio que fortalece y (re) mide la práctica de la libertad configurada en las posibilidades de liberación de los sujetos.

Palabras clave: Pedagogía freireana. Educación. Dialogo. Practica de libertad.

\section{Abstract}

The object of this study is the analysis of the work Pedagogy of the Oppressed in a critical perspective, seeking to reflect on the limitations and potential of education and dialogue in its relationship with the practice of freedom. The focus is on understanding how the work contributes to problematize criticism and dialogue with the transforming function of education, in view of the perspective of what is explained in the book. It examines how the Freirean proposal for education can think and carry out actions permeated by dialogue and that result in the formation of subjects capable of acting within the scope of the practice of freedom. The reflection is built by looking at a critical-reflexive "what to do", since the formation of the subject is treated as something dynamic that (re) builds in the movement of the pedagogical process. The methodological itinerary of the study, which is eminently bibliographic, takes, in particular, chapter 3 "Dialogicity, essence of education as a practice of freedom", considering facilitating aspects, challenges and incompleteness, both of the subjects and of the training processes. The text points out the fundamentals of Freire's pedagogy that base the dialogue as a principle that strengthens and (re) measures the practice of freedom that is configured in the possibilities of subjects' liberation.

Keywords: Freirean pedagogy. Education. Dialogue. Freedom practice.

\section{Introdução}

A obra Pedagogia do Oprimido, escrita em 1968 (lançada em 1970 em Nova York) pelo educador brasileiro Paulo Freire, expressa as sínteses atentas que foram realizadas em seu período de exílio no Chile, tempo este em que auxiliou na realização de experiências de educação popular naquele país. Ao refletir sobre a referida obra é indispensável atentar para a sua proposta de criar uma nova pedagogia que tratasse do estreitamento da relação educador(a)-educando(a)-mundo, considerando a politicidade da educação.

Para Carlos Alberto Torres (2008), Pedagogia do Oprimido de Freire e Educação e Democracia de John Dewey são os dois livros que marcaram importantes 
desenvolvimentos da filosofia da educação no século XX. Dessa forma, o livro de Freire possui um caráter revelador de uma proposta que atenda, especialmente, as camadas populares, para que se constituam como sujeitos e agentes do seu próprio processo de construção de conhecimento, tendo sucesso editorial em vários países do mundo. Isso se deve à importância do educador Paulo Freire como mobilizador da transformação da realidade social, política, econômica, cultural e educacional.

Frente a tais questões faz-se necessário divulgar e manter viva a obra Pedagogia do Oprimido, pois se trata de um livro fundante de uma prática pedagógica situada politicamente e embasada em uma pedagogia de síntese que envolve diversas bases filosóficas (ZITKOSKI, 2007), tendo em vista que a cultura se constitui, numa sociedade de classes, majoritariamente, pelo viés da trama protagonizada e tecida pela classe dominante, sempre na perspectiva do atendimento aos interesses de classe, por meio da subordinação dos(as) mais pobres e menos escolarizados(as).

Ao nos trazer a concepção de educação libertadora, Freire anuncia no horizonte a necessidade de compreender a situação de oprimido(a), para que o sujeito se liberte da dominação da consciência alienada e submissa, com vistas a tornar-se conscientemente crítico e reflexivo. Para tanto, há o anúncio da imprescindibilidade da (re)criação de itinerários formativos/reflexivos que capacitem o sujeito para desvencilhar-se das amarras da opressão/dominação para a conquista da prática da liberdade.

Nesse sentido, é interessante considerar os feitos e efeitos da ditadura militar, que compreende o período de 1964 até 1985, que teve como marco o autoritarismo, o silenciamento, a dominação, a repressão e a tortura (física e psicológica). Remexer um contexto que por mais de vinte anos produziu submissão, alienação, acriticidade, bem como que acentuou as desigualdades sociais, consequentemente, a dependência dos(as) enfraquecidos(as) e marginalizados(as) da classe dominante, que por concentrar riquezas exponencialmente concentrou o poder político - o domínio sobre os(as) mais fracos(as).

Este estudo ao enfocar a "dialogicidade, essência da educação como prática da liberdade" (capítulo 3 de Pedagogia do Oprimido), procura refletir sobre as nossas percepções do quanto, por meio do diálogo, avançamos ou não em direção à prática da liberdade, no período pós 1985 com a redemocratização do Brasil. Para isso, é fundamental atentar para o princípio do diálogo como instrumento ou não nos espaços formativos; diálogo como mecanismo para a produção de condições objetivas para produzir ações com vistas à efetiva prática da liberdade. 
Num cenário socioeducacional que se configura e reconfigura seguindo a dinâmica das sucessivas mudanças, entende-se que o diálogo é fundamental para aprimorar a prática pedagógica, com vistas à construção de conhecimento e à ampliação da cosmovisão de mundo. Freire considera o diálogo virtuoso pelo potencial agregador de coletivos, por sua vez não pode ser a pronúncia da realidade pelo olhar seletivo de "experts", mas pelo olhar das multifaces que compõem as massas historicamente alijadas dos processos participativos, das tomadas de decisões. Nesta perspectiva, adensa-se a esta reflexão a crítica à educação que não trata da vida, que não considera o sujeito como único/singular, que habita e vive em uma sociedade plural.

A partir de pesquisa bibliográfica com foco na exegese da obra freireana, o texto ora apresentado desdobra-se em três tópicos, didaticamente separados em suas abordagens, mas inter-relacionados com o propósito de dar coesão e coerências às ideias sistematizadas. No primeiro tópico "Contextualização da obra Pedagogia do Oprimido", dá-se realce ao tempo histórico e ao modo de elaboração da obra, bem como sobre a forma como a mesma se propagou pelo mundo. No segundo tópico "A educação em relação com a dialogicidade", busca-se a partir do conceito de educação abordar o diálogo como forma de reconhecer os sujeitos como comunicadores e interlocutores de diferentes saberes. Já no terceiro tópico "O diálogo em relação com a prática da liberdade”, aponta-se a prática dialógica como mobilizadora e promotora da consciência crítica, da autonomia e da emancipação, o que pode resultar em um agir livre e politizado. Por fim, nas considerações finais procura-se destacar a relevância da obra Pedagogia do Oprimido, especialmente, do recorte realizado tratando do diálogo como agregador e mobilizador dos sujeitos rumo à prática da liberdade.

\section{Contextualização da obra Pedagogia do Oprimido}

Ao iniciar esse tópico do estudo, destacamos que o livro em análise foi escrito na modalidade de ensaio, dividido em quatro capítulos: a) Pedagogia do Oprimido: justificativa; b) Educação Bancária: instrumento de opressão; c) Dialogicidade: essência da educação como prática da liberdade; d) A teoria da ação antidialógica. A obra foi lançada inicialmente em 1970 em Nova York, sendo publicada em Portugal em 1972 e no Brasil, devido a sua proibição, somente em 1974.

O próprio autor considera que "todos os livros têm sempre uma longa história, e eu vivi aproximadamente um ano falando da pedagogia do oprimido" (FREIRE, 
2014, p. 335). Em seu reencontro com o livro 25 anos depois, escreve em sua Pedagogia da Esperança: "foi vivendo a intensidade da experiência da sociedade chilena [...] que me fazia re-pensar sempre a experiência brasileira [...] escrevi a Pedagogia do oprimido entre 1967 e 1968" (FREIRE, 2008, p. 53). Inicialmente, os três primeiros capítulos eram a totalidade da obra, sendo que o quarto capítulo fora escrito por Freire depois de seis meses sem contato com o manuscrito.

Pedagogia do Oprimido revela um dos traços potentes da produção freireana: a práxis (relação teoria e prática). Isso se deve ao contexto em que esse livro, como de resto a quase totalidade da bibliografia do autor, foi produzido. Em Freire, não há uma teoria engendrada em bases especulativas abstratas e depois testada em situações concretas do cotidiano: ao contrário, o que percebemos são textos que brotam de experiências de in(ter)venção do autor, sendo seus escritos sínteses teórico-práticas de práticas politicamente situadas.

Dessa forma, o início do célebre prefácio de Ernani Maria Fiori é representativo do lugar de produção autoral de Paulo Freire. Para Fiori (2005, p. 7): "Paulo Freire é um pensador comprometido com a vida: não pensa ideias, pensa a existência”. Por isso, sua obra vai ser uma construção que parte dos desafios das sociedades desiguais e se compromete, para além da reflexão rigorosa, com a transformação de cenários injustos. Portanto, podemos considerar que é a consciência da prática que gera sua teoria, pois:

[...] a Pedagogia do Oprimido é filosofia, sociologia, educação e, sobretudo, um tratado de epistemologia. É um livro nascido da luta empreendida por seu autor para dar aos indivíduos de todas as classes sociais o direito de serem sujeitos de seu próprio processo de conhecimento e para despertar, nesses indivíduos, o interesse, a agudeza e a coragem necessários a fim de participarem do processo de transformação de suas sociedades (BARBOSA, 2017, p. 25).

O livro em tela é parte de uma extensa obra dedicada à construção de fundamentos pedagógicos que se desdobram da assunção de um projeto societário. A sua escrita no Chile é parte de um contexto mais amplo em termos políticos que situa o texto historicamente. Freire estava exilado pelo governo autoritário inaugurado no Brasil em 1964. Seu "crime" foi a proposta efetiva de alfabetização de adultos(as) como parte de um projeto de conscientização mais amplo.

Ao entender que as pessoas adultas já leem o mundo, Freire provoca a alfabetização como um processo cognoscente que deve partir dessa leitura inicial da realidade e superá-la com a leitura da palavra, não dicotomizando ou criando hierarquias entre esses dois momentos. Assim, a leitura da palavra potencializa a leitura de mundo, esta originária da experiência cotidiana e aquela do processo pedagógico. 
Nesse sentido, a concepção educacional de Freire parte de um entendimento antropológico de que as pessoas são seres inacabados exatamente pela sua condição de seres culturais. Ao diferenciar cultura e natureza, o autor provoca uma teoria crítica da construção educativa, uma vez que tudo que é cultural é socialmente produzido e pode ser problematizado. Assim, se a natureza é um dado, a sociedade é uma construção. Percebemos que, em Educação como prática da liberdade (escrito em 1965), Freire (2007) esboça essa dimensão a partir do aporte da fenomenologia e articula aquilo que seria conhecido por seu método.

Dessa forma, antes de Pedagogia do Oprimido encontramos textos que sintetizam as influências das primeiras experiências formativas de Freire e do ambiente do nacional-desenvolvimentismo e da chamada democracia populista em voga no Brasil. Duas obras - Educação e atualidade brasileira (2003) e Educação como prática da liberdade (2007) - escritas no final dos anos 1950 e início dos anos 1960 marcam aquilo que Scocuglia (2001) denomina "primeiro Paulo Freire", ou seja, um período de produção do autor marcado pela ideia de desenvolvimento nacional em termos da democracia burguesa/liberal e pela busca da conscientização.

Os três primeiros capítulos fundantes de Pedagogia do Oprimido serão um aprofundamento das discussões metodológicas presentes em Educação como prática da liberdade, sinalizando para uma obra em constante movimento de reelaboração e reconstrução. O quarto capítulo já marca uma percepção teórica assentada nos conflitos sociais e na necessidade de tomada de consciência para a ação transformadora. Isso justifica uma pedagogia do oprimido, não para oprimidos e oprimidas. Em Pedagogia do Oprimido encontramos "[...] um processo educativo para a 'revolução da realidade opressora', para a eliminação da 'consciência do opressor introjetada no oprimido', via ação político-dialógica” (SCOCUGLIA, 2001, p. 67).

Nessa linha, a influência de leituras marxianas e marxistas é visível na produção freireana a partir dessa obra. Isso não significa uma aceitação literal das teses marxistas, mas a configuração estrutural da essência política da educação enquanto prática histórica e em movimento, perpassada pela segmentação de classe social. Entre tantos conceitos-chave, podemos encontrar em Pedagogia do Oprimido três categorias estratégicas, indo ao encontro do discutido por Antunes, Gadotti e Padilha (2018) ao examinarem categorias que marcam o livro e a produção do autor a partir de então. Os conceitos "diálogo", "liberdade" e "oprimido" sugerem características presentes no livro, constantes nas obras anteriores e que serão reconstruídas e aprofundadas nos textos subsequentes. 
Nesse artigo, trabalharemos com dois conceitos - diálogo e liberdade - buscando perceber suas implicações na pedagogia freireana e seus limites e possibilidades no contexto educacional e político brasileiro. De certa forma, a noção de oprimido(a) é transversal ao argumento desenvolvido, tendo em vista a opção radical (ROMÃO, 2008) do autor em favor das classes populares e subalternas. Partindo dessas bases, o trabalho de Paulo Freire vai ser paradigmático para a construção do movimento de educação popular, ainda que, passando por Freire, esse movimento não se esgote nele. Nesse sentido,

[...] há unanimidade entre os historiadores da educação popular de que ela se forma no movimento da sociedade. Se temos nomes que servem de referência é porque pessoas se dispuseram e tiveram a habilidade de captar a pedagogia que se realizava nesse movimento. No entanto, enquanto processo, ela é maior que cada um desses nomes e continua sendo recriada nesse movimento da sociedade (STRECK, 2010, p. 300).

A publicação de Pedagogia do Oprimido oferta sínteses teóricas de alta relevância para o trabalho de base junto a movimentos populares do campo e da cidade. A problematização teórica realizada por Freire sinaliza para a unidade entre ação e reflexão, constituindo elemento-chave para a transformação da realidade. $\mathrm{O}$ diálogo seria a expressão tanto do compromisso ético (respeito pelos diferentes saberes), como da perspectiva libertadora, na qual o "dizer a sua palavra" é fundante do sujeito histórico.

Dessa forma, a formação humana e a luta política constituem espaços pedagógicos que potencializam pessoas e coletivos à conscientização acerca do mundo que é produzido historicamente (SCHNORR, 2001). Por isso, a defesa do autor das relações dialéticas entre teoria e prática e o trabalho ao nível da práxis transformadora. Assim, nem o ativismo (ação em detrimento da teoria) e nem o "verbalismo" (teoria em detrimento da ação) produziriam o ambiente transformador.

A transformação social seria um imperativo diante da desigualdade social. Freire observava essas contradições materiais e simbólicas tanto nos anos 1960 como nos anos 1990, quando, seguindo suas práticas e reflexões, produz um conjunto de textos que mostram o movimento de sua obra. Para ele,

[...] minha terra é a coexistência dramática de tempos díspares, confundindo-se no mesmo espaço geográfico - atraso, miséria, pobreza, fome, tradicionalismo, consciência mágica, autoritarismo, democracia, modernidade e pós-modernidade. O professor que na universidade discute a educação e a pós-modernidade é o mesmo que convive com a dura realidade de dezenas de milhões de homens e de mulheres que morrem de fome (FREIRE, 2006, p. 26). 
A atualidade do pensamento pedagógico de Paulo Freire passa por sua capacidade de produção teórica articulada com a prática, produzindo uma característica muito presente em sua obra: a escrita autobiográfica e situada, ou seja, que parte de contextos e experiências concretas vivenciadas pelo autor. Assim, o texto de Freire parte de suas memórias e de sua apreensão da realidade que o cerca. Ao reafirmar e problematizar a Pedagogia do Oprimido nos anos 1990, Freire é preciso ao afirmar sua metodologia de trabalho:

[...] depois de certo tempo de viver a experiência, sobretudo na medida em que se amiudou, comecei a procurar situá-la no quadro em que se dava. Que elementos cercavam ou faziam parte do momento mesmo em que me sentia mal. Quando o mal-estar era pressentido, eu procurava rever e relembrar o que ocorrera no dia anterior. Reescutar o que dissera e a quem dissera, o que ouvira e de quem ouvira. Em última análise, comecei a tomar meu mal-estar como objeto de minha curiosidade. "Tomava distância" dele para apreender sua razão de ser (FREIRE, 2008, p. 29-30).

Essa forma de produção é entendida, dentro de certas tradições acadêmicas, como "menos rigorosa", como apenas ensaios gerais sobre educação. Mas, Freire, ao seu tempo, antecipava-se a tendências de escrita que configuram o denominado "paradigma emergente", nos termos de Boaventura de Sousa Santos. Nessa linha, ao problematizar elementos constitutivos da ciência moderna, Santos (2009) advoga por novas formas de conhecimento que sejam compreensivas, nas quais o caráter autobiográfico e autorreferenciável da ciência é legítimo.

Freire, ao ser um crítico severo ao neoliberalismo - sua ética de mercado e sua lógica naturalizadora - e de fatalismos de qualquer natureza, é um ator entendido dentro de certa "pós-modernidade progressista ou radical" (MOTA NETO, 2015, p. 9) presente na agenda de debates nos anos 1990. Esse traço engajado de sua produção, sua não aceitação em dissociar razão e emoção e sua escrita plural, o constituem em foco de adesões e resistências no meio acadêmico e na sociedade em geral.

Em três décadas de reflexões sistemáticas sobre política, cultura e educação, Freire nos oferta uma filosofia da educação com implicações nas mais diferentes áreas do conhecimento. Essa característica interdisciplinar de sua obra tem na Pedagogia do Oprimido um marco fundamental. Freire é um autor que explicita posições e consegue se manter aberto a um diálogo profícuo com as mais diversas tradições de pensamento, produzindo sínteses que desacomodam "puristas" acadêmicos(as) e sectários(as) políticos(as), ao mesmo tempo que seduz pessoas comprometidas com o espírito democrático. No seu livro de maior reconhecimento é possível percebermos que: 
[...] sem desconsiderar o fato de seu solo fértil, no qual suas ideias e ideais vicejaram, ter sido cultivado especialmente pela semeadura do materialismo histórico-dialético de inspiração hegeliana (ex.: Lukács), ele também se nutriu do grande manancial cultural da hermenêutica filosófica (ex.: Buber), do existencialismo (ex.: Sartre), da Escola de Frankfurt (ex.: Fromm) e do pensamento pós-colonial (ex.: Fanon); sem contar o pensamento teológico progressista (ex.: Chenu), o pensamento social brasileiro (ex.: Álvaro Vieira Pinto) e tantas outras correntes libertadoras (SOUZA; MENDONÇA, 2019, p. 3).

Essa intensa interlocução de Freire segue constante em sua obra depois de Pedagogia do Oprimido, mostrando sua abertura as mais distintas perspectivas teóricas. Ao examinarmos essa arqueologia bibliográfica (PITANO; STRECK; MORETTI, 2019) do autor, conseguimos entender a complexidade de seu pensamento e as inúmeras possibilidades que abriu no campo da teoria educacional. Freire é um autor conectivo, relacional e plural, que permite aproximações e diálogos com diversos(as) autores(as), o que amplia redes e novas interpretações.

Pedagogia do Oprimido é um livro que alcançou enorme circulação internacional. É uma das obras mais citadas na área de ciências humanas ${ }^{1}$ e tem muitas traduções em vários idiomas. Mesmo partindo de temas da realidade concreta da América Latina e voltado à transformação social por meio da conscientização dos(as) oprimidos(as), o livro tem boa recepção em países centrais do capitalismo.

Um dos elementos que podem explicar esse alcance, além da pluralidade de debates teóricos, é a capacidade do autor de propor uma pedagogia utópica, baseada na conscientização, no humanismo e na valorização dos saberes da experiência. Isso torna Freire um pedagogo brasileiro e mundial e a sua obra um "patrimônio essencial para a pedagogia hoje" (NÓVOA, 1998, p. 183).

Porém, sabemos que o autor, que teve uma vida intensa e uma obra em movimento permanente, não está imune às contradições de recepção de sua obra, especialmente no atual contexto brasileiro. Conceito central da Pedagogia do Oprimido e de sua obra como um todo, o diálogo é um elemento central que segue pertinente a análises rigorosas da área da educação. É por meio desse conceito que seguiremos explorando o livro fundante da pedagogia freireana em suas potencialidades e em seus limites.

\section{A educação em relação com a dialogicidade}

A trajetória de Paulo Freire se enraíza com maior vigor no Brasil no início da década de 1960 e no mundo pós-1964, quando foi para o exílio no Chile (depois de rápida passagem pela Bolívia), com o advento da ditadura militar. Desde sempre 
existiu/existe encantamento pela pedagogia de Freire; por outro lado há tentativas de negação de suas teorias. Por sua vez, os(as) educadores(as) freireanos(as) historicamente têm militado em favor da implementação de uma educação libertadora; já os(as) que negam a pedagogia freireana colocam-se alinhados(as) com as práticas "tradicionais", "conservadoras" na linha da chamada educação "bancária”, na qual, sendo uma das marcas da opressão, o ato de "depositar" informações/conhecimentos pelo(a) professor(as) nos(as) estudantes é a tônica. Assim, cabe destacar, neste início de seção, que o legado de Freire traz consigo a motivação e a possibilidade de as classes populares tornarem-se sujeitos e agentes da transformação da realidade social, produzindo novas possibilidades educativas e sociais de forma ampla.

Ao referir-se à educação como prática da liberdade, Freire faz críticas contundentes à classe dominante que, ao negar a palavra aos diferentes sujeitos, busca mantê-los submissos e oprimidos. Negar a palavra - o diálogo - é um bom pretexto para manter os oprimidos alienados e sob a manipulação, o que não gera ações que favorecem a liberdade. O diálogo constitui-se em instrumento para que os sujeitos em condição de subalternidade possam enfrentar e superar as situações que os oprimem, buscando restaurar o seu lugar de sujeito no e com o mundo. Para Freire (1987, p. 20), o diálogo deve ser “[...] essencialmente tarefa de sujeitos e que não possa verificar-se na relação de dominação". O autor segue indicando o amor como antídoto à dominação, haja vista que "[...] amor é compromisso com os homens. Onde quer que estejam estes oprimidos, o ato de amor está em comprometer-se com sua causa. A causa de sua libertação" (1987, p. 20).

Trazer a amorosidade e o diálogo para o campo da educação, como sugere Freire, é um exercício que necessita ser realizado para refletir sobre quanto os processos de escolarização no Brasil, ainda, conservam formas de regulação moral e política. Ao refletir criticamente acerca das práticas educativas antidialógicas, faz-se necessário entender o poder dessas práticas como reprodutoras de injustiças sociais e do fortalecimento de ações pedagógicas conservadores e mecânicas. Assim, o diálogo enquanto oposição ao antidiálogo torna-se exigência radical para que os homens e as mulheres sejam interlocutores(as), utilizando os mais variados espaços de comunicação. Desse modo, “obstaculizar a comunicação é transformá-los [os homens e mulheres] em quase 'coisas' e isto é tarefa e o objetivo dos opressores, não dos revolucionários" (FREIRE, 1987, p. 125).

Enlaçado a isso, cabe questionar de que forma na escola se estabelecem os canais de diálogo/comunicação entre os vários segmentos da comunidade escolar? O diálogo apontado por Freire, como recurso indispensável para estreitar as rela- 
ções entre sujeitos, corrobora a ideia de que a educação é um processo relacional. Em Giroux (1997, p. 125), estudioso da pedagogia freireana, encontra-se que a prática pedagógica deve facilitar que professores(as) e estudantes "[...] assumam o papel crítico e reflexivo de intelectuais transformadores". No campo educacional é fundamental frisar que o diálogo funciona como mecanismo para produzir visões crítico-reflexivas sobre a realidade social - sobre o mundo.

As práticas e as diferentes modalidades pedagógicas, histórica e socialmente inseridas no discurso e na corporificação teórica e ideológica dos(as) professores(as), conforme Freire (1987), precisam valorizar a "palavra" daqueles(as) que sempre lhes foi imposta a condição de "ignorantes" pela elite. O espaço de fala - da voz e da vez -, especialmente, pós-1985, ano que marca a redemocratização no Brasil, tem permeado problematizações e debates em algumas instituições que oferecem cursos de formação de docentes e que primam pela reflexão e produção de conhecimentos teórico-metodológicos. Isso, sem dúvida, em várias instituições formadoras acontece/aconteceu, mas qual a razão de termos avançado tão pouco no processo de conscientização e de construção de práticas participativas, dialógicas e democráticas?

Certamente, as variáveis que se entrecruzam nos contextos formativos escolares e não escolares estão eivadas por contradições do ponto de vista das concepções teóricas, especialmente sobre o que se entende por educação $0^{2}$, ensino e aprendizagem (PAVIANI, 1986). No período de 50 anos da Pedagogia do Oprimido, é preciso considerar os diferentes modos de como se configurou e reconfigurou o tecido social e a própria cultura escolar. Esses aspectos podem nos ajudar a compreender sobre o quão pouco conseguimos avançar na perspectiva de uma educação emancipadora e libertadora.

A despeito disso, entende-se que a formação docente por si só não é suficiente para as transformações da educação e, consequentemente, da sociedade, tendo em vista que a cultura escolar entranhada no modo de ser professor(a) também obstaculiza avanços na direção de práticas educativas para enfrentar e superar a concepção "bancária" de educação, que por ser antidialógica reproduz a consciência ingênua e acrítica.

Sabemos que há resistências que perpassam o cotidiano escolar, principalmente a forma como gestores(as) e educadores(as) concebem a docência, muitas vezes, castradora de boas ideias e de boas práticas daqueles professores que tiveram uma formação crítico-reflexiva, com potencial para realizar intervenções significativas para a mudança do cenário educacional. Entende-se que o enfrentamento do modus 
operandi da docência passa também pelo enfrentamento das concepções conservadoras a respeito da escola, sendo que não pode haver construção de conhecimento se os(as) estudantes não forem chamados(as) para desenvolver o "ato de conhecer", mas apenas para memorizar os conteúdos narrados pelo(a) professor(a) (FREIRE, 1987).

Ao retornar do exílio, com a Lei da Anistia, Freire se desafia a refletir junto com os educadores e as educadoras do Brasil aspectos que se relacionam com a prática pedagógica, tendo em conta o movimento gnosiológico dos sujeitos, bem como as diferentes alternativas para dinamizar os atos cognoscentes com vistas a tornar os objetos (conteúdos) cognoscíveis. Entre as multifaces que se entrecruzam na prática docente está:

[...] a do mau hábito de pensar um pensar estático, não dinâmico, não dialético, em que a gente separa quase milagrosamente (porque, na verdade, não se pode separar), mas em que a gente dicotomiza, por exemplo, a prática pedagógica, a prática educativa, a ação educativa, da preparação da ação da mesma, em que a gente separa a preparação da ação, da avaliação, em que a gente separa os métodos dos conteúdos e os métodos e os conteúdos dos objetivos (FREIRE, 1984, p. 91).

No momento em que se retoma a reflexão sobre a prática pedagógica, tendo como ponto essencial a educação escolar, é interessante considerar que esta se desenvolve, em algumas instituições, consciente ou inconscientemente embasa em concepções, ora de "educação bancária" ora de "educação problematizadora". Ao ter ciência de tais modelos de fazer "educações" na escola, é que Freire toma o mote da educação problematizadora, investindo tempo e, sobretudo, buscando difundir sua pedagogia em favor do desenvolvimento dos sujeitos como atores construtores do seu próprio conhecimento.

Ao ter presente que o potencial do diálogo que se estabelece entre o binômio educador(a)-educando(a), Freire (1987, p. 68) sugere que “[...] o educador já não é o que apenas educa, mas que, enquanto educa, é educado, em diálogo com o educando que, ao ser educado, também educa". É desta assertiva que se pode inferir que o caráter individualista do(a) educador(a) que apenas ensina está superado, haja vista que a dialogicidade é reveladora de diferentes saberes que estão latentes na experiência $\operatorname{dos}($ as) educandos(as0 e, que tais saberes no diálogo com os saberes dos(as) educadores(as) resultam em novos saberes para ambos (educador(a)-educando(a)).

Desse modo, a reflexão crítica sobre a realidade e sobre as experiências cotidianas dos(as) estudantes não ocorre no silêncio, supostamente estruturado como disciplinador das relações em sala de aula. Ao contrário, sugere a pré-disposição ao diálogo para inquirir e questionar as estruturas de dominação existentes, mas 
que buscam representar um falso quadro de harmonia entre as classes. Harmonia que, conforme Giroux (1997), não é mais do que uma retórica para dizer aos(às) subordinados(as) que sofrem as injustiças que devem "aceitar" a desigualdade de classes como algo dado e natural.

Neste recorte em que se aponta a educação em relação com a dialogicidade, de acordo com Freire (1987), pode-se dizer que a prática educativa requer do(a) professor(a) a adoção da problematização como possibilidade de os(as) estudantes superarem a ideia de conhecimento como doxa, substituindo-o pela ideia de conhecimento que se constrói através do logos. Assim, o conhecimento produzido na perspectiva do logos, procura por meio da emersão dos fenômenos, produzir alternativas de inserção crítico-social dos sujeitos na realidade em busca de sua transformação. Esse cenário é indutor de uma pedagogia que, baseada no diálogo, é um exercício crítico de liberdade.

\section{0 diálogo em relação com a prática da liberdade}

O diálogo em relação com a prática da liberdade requer que se retome a abordagem do diálogo como princípio pedagógico, o qual encerra possibilidades interativas e integrativas. Enlaçado a isso, temos a educação problematizadora como possibilidade de libertação fundamentada na crítica, que é produzida por meio da reflexão-ação-reflexão e da criatividade dos(as) humanos(as) "[...] que não podem autenticar-se fora da busca e da transformação criadora" (FREIRE,1987, p. 72).

A relativa consideração à obra Pedagogia do Oprimido de Paulo Freire, que em tempos de quase interdição ao pensamento crítico procura menosprezar e desqualificar a pedagogia freireana; o discurso concordante com a teoria de Freire passa, então, neste momento histórico, a enfrentar a violência simbólica, que é contra uma proposta visivelmente a favor da "educação como prática da liberdade". Nessa perspectiva, torna-se relevante rever a alusão de Freire (1979, p. 12, grifos do autor) sobre o diálogo como âncora facilitadora à prática pedagógica problematizadora:

[...] há limites para o diálogo. Porque numa sociedade de classes não há diálogo, há apenas um pseudodiálogo, utopia romântica quando parte do oprimido e ardil astuto quando parte do opressor. Numa sociedade dividida em classes antagônicas não há condições para uma pedagogia dialogal. O diálogo pode estabelecer-se talvez no interior da escola, da sala de aula, em pequenos grupos, mas nunca na sociedade global. Dentro de uma visão macro-educacional, onde a ação pedagógica não se limita à escola, a organização da sociedade é também tarefa do educador. E, para isso, seu método, sua estratégia, é muito mais a desobediência, o conflito e a suspeita do que o diálogo. 
O excerto reforça que os escritos de Freire, ainda, são hodiernos. Contudo, em tempos de obscurantismo o(a) docente compromissado(a) com a interlocução com seus(suas) estudantes e com a produção da consciência crítica, necessita, permanentemente, refletir e (re)situar no tempo e na história a sua atuação pedagógica. Assim, se nos momentos compreendidos entre 1985-2015 (três décadas), por ser um tempo de maior abertura política e democrática, era um tanto difícil atuar na perspectiva crítico-reflexiva, nos dias atuais pode ser considerado dificílimo (não impossível), devido ao recrudescimento do ideário autoritário e centralizador, tanto no Brasil como em outros países do mundo.

Passadas três décadas é de se perguntar se produzimos consciência crítica ou se simplesmente nos iludimos em ter produzido entre as massas conscientização e politização? Era, pois, de se esperar que neste período, por meio dos espaços formativos escolares e não escolares, tivéssemos forjado a formação de seres humanos potencialmente compromissados(as) com o mundo, com a história e com a humanização das massas oprimidas. Para a produção de massa crítica e de cidadãos e cidadãs conscientes, compreende-se que não há mais como ignorar dos processos educativos a sociedade de classes e suas profundas desigualdades, a precarização das condições de produção da subsistência, as questões de raça, etnia, gênero; aspectos estes que explicitam suas marcas diretamente em sala de aula, por fazerem parte da história e da experiência de vida dos(as) educandos(as) e docentes.

Ao debater sobre as mazelas da realidade social e dos sujeitos nela inseridos, serão referenciadas denúncias sobre a vida e sobre a desumanização, todavia, conforme Freire (2001) isso não basta, ou seja, a denúncia ao ser acolhida pela consciência requer atitudes no formato de anúncios e possíveis ações. O caráter utópico da educação com vistas a concretizar a prática da liberdade parte da premissa de que a denúncia sobre a realidade representa o ponto de partida para o anúncio de ações transformadoras (FREIRE, 2001).

Desse modo, a ação transformadora

[...] utópica e esperançosa porque, pretendendo estar a serviço da libertação das classes oprimidas, se faz e se refaz na prática social, no concreto, e implica a dialetização da denúncia e do anúncio, que têm na práxis revolucionária permanente, o seu momento máximo (FREIRE, 2001, p. 70).

Talvez seja oportuno pensar criticamente sobre os avanços dos conhecimentos na área das ciências humanas, principalmente, aqueles alinhados com a pedagogia freireana, mas que efetivamente pouco interferiu na prática docente - na organi- 
zação e desenvolvimento de ações pedagógicas capazes de tornar a educação libertadora e emancipadora.

Em termos de escolarização não se pode esperar que o futuro seja melhor se a ação pedagógica continuar sendo mera repetição de conteúdos sem vínculo com a realidade micro e macrossocial. Nesse sentido, "quanto mais a problematização avança e os sujeitos descodificadores se adentram na 'intimidade' do objeto problematizado, tanto mais se vão tornando capazes de desvela-lo" (FREIRE, 2001, p. 77).

Para debater a realidade social em sala de aula é fundamental que o professor adote estratégias para tornar o ambiente e a relação entre docente-discente e discente-discente crítica, mas respeitosa. A razão disso é que ao tratar de temáticas polissêmicas podem aparecer entre os envolvidos (estudantes) resistências, pelas dificuldades de reconhecer e decodificar as tramas que tecem a história e a realidade social. É essencial, desse modo, conduzir o processo pedagógico no horizonte freireano em que a educação é um ato político. Então, aquele(a) que argumenta o contrário,

[...] afirmando que o educador não pode "fazer política", estão defendendo uma certa política, a política da despolitização. Pelo contrário, se a educação, notadamente a brasileira, sempre ignorou a política, a política nunca ignorou a educação. Não estamos politizando a educação. Ela sempre foi política. Ela sempre esteve a serviço das classes dominantes (FREIRE, 1997, p. 14).

Em relação à citação é preciso ter o entendimento que se a educação é um ato político, por sua vez, a escola é um espaço em que se faz política. É fundamental destacar que a escola é uma construção social, portanto, uma construção política e intencional, por isso, está sempre em disputa, o que é salutar para que os espaços formativos sejam democráticos e emancipadores. Enfatiza-se, dessa maneira, que a prática pedagógica para fundamentar a prática da liberdade, requer enfrentamentos e decisões, não descuidando da articulação dos objetivos, conteúdos, procedimentos metodológicos e avaliação. A despeito disso, corrobora Giroux (1997) quando indica que a experiência do estudante necessita ser privilegiada não apenas para compartilhar atributos, mas para refletir e produzir conhecimentos e consciência crítica. Dessa forma,

[...] [a] visão acrítica dos estudantes, particularmente daqueles pertencentes a grupos subordinados, está refletida na recusa do discurso da relevância em examinar criticamente a maneira pela qual o mesmo fornece e legitima formas de experiência que incorporam a lógica de dominação (GIROUX, 1997, p. 129). 
O debate sobre a real situação e condição de pertencimento de classe social, deve servir para que os sujeitos reconheçam em que lugar social estão situados, bem como as razões que os situaram neste lugar. A partir desta compreensão, ao contrário de acomodarem-se às condições a que socialmente estão submetidos, por meio do conhecimento e da consciência de classe, devem organizar-se e lutar, identificando no movimento em que os homens e mulheres permanentemente encontram-se inscritos(as), "[...] como seres que se sabem inconclusos; movimento que é histórico e que tem o seu ponto de partida, o seu sujeito, o seu objetivo" (FREIRE, 1987, p. 73). Nessa perspectiva, é interessante em uma análise, partir da condição desumanizante, a busca da construção de uma realidade em que os homens e as mulheres se empoderem para "ser mais" - compromisso histórico e utópico da ação para a liberdade.

De acordo com Freire (2001, p. 96), "a consciência crítica não se constitui através de um trabalho intelectualista, mas na práxis - ação e reflexão”. Como já destacado, Freire (1987) compreende a práxis como atividade humana e social, que se ocupa do poder que o ser humano tem para produzir a unidade: teoria-prática; homem/mulher-mundo; sujeito-objeto; objetividade-subjetividade. O espaço escolar, dessa maneira, não poderia negar às classes dominadas momentos para denúncias, nem tampouco deixar de auxiliar na construção de possibilidades que fortaleçam anúncios teórico-práticos com vistas à transformação da realidade. Isso encontra eco no fato de que a ação que se constitui em favor da libertação se constrói em oposição aos interesses das classes dominantes (FREIRE, 2001).

A educação que se realiza com o propósito de que tanto educadores(as) como educandos(as) se tornem sujeitos de seu processo, faz-se "[...] aprofundando a tomada de consciência da situação, os homens se 'apropriam' dela como realidade histórica, por isto mesmo, capaz de ser transformada por eles" (FREIRE, 1987, p. 74). Essencial à produção da consciência crítica é articular os conhecimentos curriculares com as problemáticas que se colocam como condição natural à manutenção do status quo da classe dominante.

A prática da liberdade, a partir do diálogo estabelecido em sala de aula e na escola, se expressa: na competência e no argumento fundamentado teoricamente; na compreensão do tecido social que se configura com base na matriz do capitalismo; na capacidade de organização das classes subordinadas para saírem da condição de passividade e silenciamento, assumindo a condição de sujeito empoderado pela palavra - pelo conhecimento como ferramenta do poder. 
Nesse sentido, é apropriado destacar que, na perspectiva freireana, liberdade não significa licenciosidade, sendo que a liberdade necessita da autoridade (GHIGGI, 2001). Portanto, ao defender uma educação dialógica, não autoritária e situada politicamente em um projeto solidário e inclusivo de sociedade, a leitura rigorosa da obra de Freire a afasta de posturas doutrinadoras de qualquer natureza. Pelo contrário, a teoria e prática do autor o situam como um humanista preocupado com a radicalidade democrática.

Em Pedagogia do Oprimido encontramos uma posição política que se desdobra em uma proposta pedagógica. O diálogo ocupa lugar central na filosofia da educação freireana exatamente por ser um mecanismo da prática da liberdade. Ao dizer a sua palavra, homens e mulheres potencializam sua condição humana e, assim, podem construir a consciência crítica que aprofunda sua leitura de mundo.

Contudo, o que explicaria a continuidade de práticas pedagógicas autoritárias na escola do século XXI? Quais os limites do diálogo em nossa sociedade marcadamente desigual? Quais as variáveis que ajudam a explicar o atual quadro da ofensiva conservadora no Brasil? Qual o partido daqueles(as) que defendem uma "escola sem partido"? Entendemos que essas e outras questões nos desafiam na apreensão crítica do cenário atual, em que a Pedagogia do Oprimido segue atual em suas bases teóricas e compromissos políticos. Assim, uma pergunta-chave desse contexto é: "como é possível que, mundo afora, as edições de seus livros sejam lidas por milhões e aqui se pretenda expurgá-lo da educação brasileira?” (KOHAN, 2019, p. 22). O enfrentamento dessa questão é um exercício crítico do quadro político nacional e das históricas disputas de poder e projetos de país.

\section{Considerações finais}

O desafio de dialogar com a obra de Freire, especialmente com a Pedagogia do Oprimido no momento contemporâneo pelo qual passa o Brasil, redobra nosso compromisso em levar adiante o legado freireano, que postula por uma educação libertadora e que, ao ser mediada pelo diálogo, se configure como prática da liberdade. Para tanto, atenta-se para a necessidade de (re)situar conceitos e práticas, com vistas à reconstrução de cenários que reavivem ações colaborativas e participativas. Assim, o diálogo como uma das possibilidades para problematizar a vida e a realidade é imprescindível para a construção de conhecimentos, que ocorrem na relação docente-discente, não pela mera narrativa de conteúdos pelo(a) professor(a). 
Se o diálogo tem potencialidades para discutir, debater, problematizar, indagar, inferir, contra-argumentar, cabe pensar sobre aspectos que não permitiram avançar em ações que efetivamente produzissem as condições para o exercício da prática da liberdade, em um tempo histórico (1985-2015), em que se vislumbrava a viabilidade de construções democráticas. Se não avançamos o quanto poderíamos de 1985 até 2015, cabe refletir por que, em um espaço relativamente curto (20162020), houve um acentuado recrudescimento na tomada de decisões em espaços coletivos e participativos.

Nesse sentido, percebe-se um processo acelerado de tentativa de castração da criatividade, da curiosidade, da inventividade. Entende-se, pois, que, se tanto educadores(as) como educandos(as) estão encharcados(as) desta realidade "perversa", que visa silenciar mentes, corpos e a voz, é mister eleger conhecimentos curriculares que favoreçam a compreensão da realidade, para enfrentar as práticas enviesadas e com caráter dogmático e autoritário nas escolas.

O tempo "perdido" em termos dos possíveis avanços que poderiam ter ocorrido de 1985 a 2015 necessita ser visualizado com cautela, na perspectiva do movimento histórico em suas contradições. Houve, a partir do início da década de 1970 - período do auge da ditadura militar -, uma significativa expansão da educação básica na rede pública do ensino brasileiro, que demandou a formação de professores(as). Cabe, então, debruçar-se sobre com que proposta e com que formato de curso foram "formados(as)" os(as) professores(as) que seguiram o exercício da docência na transição do período da ditadura militar ao período pós-1985, denominado de "redemocratização do Brasil”.

É essencial, também, pensar como à época se apresentava o perfil dos formadores para os cursos de graduação aligeirados e desdobrados entre licenciatura de curta duração (LC) e licenciatura plena (LP), nos termos da Lei oㅜ 5.692/1971. Com isso, não se pretende tecer considerações superficiais e ingênuas, culpabilizando somente os(as) docentes pelos supostos "não avanços" da proposta de educação libertadora, apontada por Freire na obra Pedagogia do Oprimido, com vistas à emancipação do sujeito e à sua preparação para o exercício consciente da cidadania. Pode-se dizer que há um conjunto de variáveis que concorrem para o entendimento ou não de que a escola pode conquistar sua autonomia, construindo seu projeto político-pedagógico de forma coletiva, envolvendo toda a comunidade escolar.

Envolver a comunidade escolar em processos coletivos para debater, tomar decisões e encaminhar ações no campo pedagógico não é tarefa fácil, pois as escolas, de maneira antidialógica, foram pensadas pelo sistema por mais de duas décadas (di- 
tadura militar). Na perspectiva freireana, quem não pensa é pensado, ou seja, os órgãos centrais dos sistemas planejavam e as escolas executavam, não havia proposta pedagógica própria e tampouco regimento escolar próprio, era responsabilidade da mantenedora (estado ou município) enviar às unidades escolares para o "cumpra-se".

Os aspectos aludidos também corroboraram para a limitação da expansão e evolução da pedagogia freireana nas escolas, talvez uma das causas esteja na dificuldade dos atores educacionais não se sentirem pré-dispostos, compromissados, capacitados para assumir o protagonismo de pensar a escola como um lugar essencial para a existência humana, para construir ações com vistas a libertar o sujeito das amarras do pensar estático, acrítico e ingênuo.

Toda a ação humana se realiza balizada por uma concepção política e ideológica, sempre entremeada por contradições, tensionamentos, conflitos, incertezas, que devem passar pelo crivo reflexivo da "pergunta em favor de que e contra que, em favor de quem e contra quem eu conheço, nós conhecemos, não há mais como admitir uma educação neutra a serviço da humanidade, como abstração" (FREIRE, 1984 , p. 97, grifos do autor). Sem dúvida, ao assumir que a educação não é neutra, é essencial compreender que tanto a educação bancária como a problematizadora estão eivadas de poder, respectivamente, alienador e libertador.

Isso aponta para a necessidade de entender a educação como ato político, que precisa ser assumida como prática política e social. O fato de não assumir a prática docente como uma prática consciente e politizada, também representa um dos motivos em avançar na dialogicidade e na ascensão da prática da liberdade. Mesmo enfrentando alguns obstáculos de ordem epistemológica e teórico-conceitual, é premente que os(as) militantes progressistas do campo educacional permaneçam firmes na defesa de uma educação autêntica, "mediatizada pelo mundo" (FREIRE, 1987, p. 84).

Para o(a) educador(a) humanista, a saída do "contexto colonial" não se dará pela imposição de um dado conhecimento, mas pode ser produzido pelas "visões impregnadas de anseios, de dúvidas, de esperanças ou desesperanças que implicitam temas significativos à base dos quais se constituirá o conteúdo programático da educação" (FREIRE, 1987, p. 84). De modo geral, demanda-se ainda muito esforço da categoria docente para entender a magnitude em assumir a posição de ator/ sujeito protagonista, não apenas como coadjuvante, mas como orgânico no processo da configuração do diagnóstico da realidade, envolvendo-se efetivamente também na elaboração, execução e avaliação do projeto educativo e curricular da escola.

O alcance da autonomia político-pedagógica não se constitui em uma tarefa fácil, pois a complexidade da realidade não pode ser ignorada; precisa ser confron- 
tada para que a ideia de mudança social perpasse o planejamento dos processos formativos, afirmando-se nos objetivos educacionais que estruturam as práticas escolares (GIROUX, 1997). A escola, desse modo, não pode operar na perspectiva de que "o silêncio estruturado que subjaz o seu único 'nossa' sugere não haver disposição para indiciar ou questionar as estruturas de dominação existentes, enquanto apela para uma harmonia artificial" (GIROUX, 1997, p. 133).

O discurso da harmonia que não coloca em debate e questionamento as injustiças experimentadas pelas classes subalternas, historicamente alijadas de uma vida digna e de condições para produzir a própria subsistência, carece de situar os homens que "não somente vivem, mas existem, e sua existência é histórica" (FREIRE, 1987, p. 89). No enlaçamento com a pedagogia freireana, se os homens e as mulheres tiverem a consciência de que sua relação com o mundo é situada, datada e, especialmente, produzida pelo viés da matriz capitalista, poderão atuar em função de finalidades propositivas e criadoras de condições objetivas para a intervenção e a transformação social.

Assim, para desvencilhar-se da relação opressor-oprimido, o diálogo é essencial para que ocorra a conscientização popular, pois não haverá "uma radical denuncia das estruturas de dominação sem o anuncio de uma nova realidade a ser criada em função dos interesses das classes sociais hoje dominadas" (FREIRE, 2001, p. 97). Sobre isso, ainda, discorre Freire (1987, p. 88) ao destacar que os "homens como os únicos seres, entre os 'inconclusos', capazes de ter, não apenas sua própria atividade, mas a si mesmos, como objeto de sua consciência, o que os distingue do animal, incapaz de separar-se de sua atividade".

Tendo ciência, talvez, do pouco que se avançou na educação brasileira sob a orientação da pedagogia de Paulo Freire, destacam-se alguns exemplos realizados em gestões municipais desenvolvidas de forma democrática e participativa, como, por exemplo, em São Paulo, Belo Horizonte e Porto Alegre. Então, ainda há muito por fazer, mas não estamos em um território de "terra arrasada", talvez em certo "estado de sítio", pelas tentativas abruptas de silenciamento daqueles(as) que vociferam a defesa da educação pública, da educação crítica e de qualidade social para todos e todas, indistintamente de classe social, raça, etnia e gênero. Tem-se clareza da limitação desta reflexão, por isso ela está aberta às devidas críticas daqueles(as) estudiosos(as) das obras de Freire, especialmente da Pedagogia do Oprimido; as críticas servirão de âncora para prosseguir no aprofundamento da reflexão acerca dos estudos freireanos. 
Por fim, como recorte deste texto, reforça-se a imprescindibilidade de enfatizar a práxis como possibilidade metodológica para agir e refletir criticamente, produzindo novos conhecimentos e novas visões sobre o processo ensino-aprendizagem. Assim, entende-se que a reflexão crítica acerca da relação teoria-prática se sustenta pela ação dialógica em vista da prática da liberdade.

\section{Nota}

1 Segundo pesquisa realizada no Google Scholar, pelo professor da London School of Economics, Elliott Gren. Maiores informações em: https://www.nexojornal.com.br/expresso/2016/06/04/Paulo-Freire-\%C3\%A9-o-terceiro-pensador-mais-citado-em-trabalhos-pelo-mundo. Acesso em: 12 mar. 2020.

2 Dentre suas diferentes conceituações, entendemos a educação em sua tarefa de oferecer "condições de opção ou possibilidade de fazer valer sua experiência de pessoas livres e responsáveis” (PAVIANI, 1986, p. 10). Portanto, a educação representa uma ação em favor da vida que favorece a invenção e reinvenção da sociedade.

\section{Referências}

ANTUNES, Angela Biz; GADOTTI, Moacir; PADILHA, Paulo Roberto. Três categorias que marcaram a Pedagogia do Oprimido. Educação em Perspectiva, Viçosa, v. 9, n. 2, p. 514-526, set./dez. 2018.

BARBOSA, Ana Mae. Sobre a Pedagogia do Oprimido. In: FREIRE, Ana Maria Araújo (org.). Pedagogia da libertação em Paulo Freire. 2. ed. Rio de Janeiro/São Paulo: Paz e Terra, 2017. p. 25-26.

FIORI, Ernani Maria. Aprender a dizer a sua palavra. In: FREIRE, Paulo. Pedagogia do Oprimido. 41. ed. Rio de Janeiro: Paz e Terra, 2005. p. 7-22.

FREIRE, Paulo. Depoimento de um grande amigo [posfácio]. In: FIORI, Ernani Maria. Educação e política. 2. ed. Porto Alegre: Editora da UFRGS, 2014. p. 321-338.

FREIRE, Paulo. Pedagogia da esperança: um reencontro com a Pedagogia do Oprimido. 15. ed. Rio de Janeiro: Paz e Terra, 2008.

FREIRE, Paulo. Educação como prática da liberdade. 30. ed. Rio de Janeiro: Paz e Terra, 2007.

FREIRE, Paulo. À sombra desta mangueira. 8. ed. São Paulo: Olho d’Água, 2006.

FREIRE, Paulo. Educação e atualidade brasileira. 3. ed. São Paulo: Cortez/Instituto Paulo Freire, 2003.

FREIRE, Paulo. Ação cultural para a liberdade: e outros escritos. 9. ed. São Paulo: Paz e Terra, 2001.

FREIRE, Paulo. Pedagogia do oprimido. 17. ed. Rio de Janeiro: Paz e Terra, 1987.

FREIRE, Paulo. Educação sonho possível. In: BRANDÃO, Carlos Rodrigues (org.). O educador: vida e morte. 5. ed. Rio de Janeiro: Graal, 1984. p. 89-101. 
FREIRE, Paulo. Educação e mudança. Rio de Janeiro: Paz e Terra, 1979.

GHIGGI, Gomercindo. A autoridade a serviço da liberdade: diálogos com Paulo Freire e professores em formação. Perspectiva, v. 19, n. 2, p. 469-492, jul./dez. 2001.

GIROUX, Henry A. Os professores como intelectuais: rumo a uma pedagogia crítica da aprendizagem. Porto Alegre: Artmed, 1997.

KOHAN, Walter. Paulo Freire, mais do que nunca: uma biografia filosófica. Belo Horizonte: Vestígio, 2019.

MOTA NETO, João Colares da. Educação popular e pensamento decolonial latino-americano em Paulo Freire e Orlando Fals Borda. 2015. 368 f. Tese (Doutorado em Educação) - Instituto de Ciências da Educação, Universidade Federal do Pará, Belém, 2015.

NÓVOA, António. Paulo Freire (1921-1997): a "inteireza” de um pedagogo utópico. In: APPLE, Michael; NÓVOA, António (org.). Paulo Freire: política e pedagogia. Porto: Porto Editora, 1998. p. 167-187.

PAVIANI, Jayme. Problemas de filosofia da educação. 8. ed. Petrópolis, RJ: Vozes, 1986.

PITANO, Sandro de Castro; STRECK, Danilo Romeu; MORETTI, Cheron Zanini (org.). Paulo Freire: uma arqueologia bibliográfica. Curitiba: Appris, 2019.

ROMÃO, José Eustáquio. Opção radical pelo oprimido. In: GADOTTI, Moacir (org.). 40 olhares sobre os 40 anos da pedagogia do oprimido. São Paulo: Editora e Livraria Instituto Paulo Freire, 2008. p. 13-14.

SANTOS, Boaventura de Sousa. Um discurso sobre as ciências. 6. ed. São Paulo: Cortez, 2009.

SCHNORR, Giselle Moura. Pedagogia do oprimido. In: SOUZA, Ana Inês (org.). Paulo Freire: vida e obra. São Paulo: Expressão Popular, 2001. p. 69-100.

SCOCUGLIA, Afonso Celso. A história das ideias pedagógicas de Paulo Freire e a atual crise de paradigmas. 3. ed. João Pessoa: Editora Universitária/UFPB, 2001.

SOUZA, Katia Reis de; MENDONÇA, André Luís de Oliveira. A atualidade da "pedagogia do oprimido" nos seus 50 anos: a pedagogia da revolução de Paulo Freire. Revista Trabalho, Educação e Saúde, Rio de Janeiro, v. 17, n. 1, 2019.

STRECK, Danilo Romeu. Entre emancipação e regulação: (des)encontros entre educação popular e movimentos sociais. Revista Brasileira de Educação, v. 15, n. 44, p. 300-310, maio/ago. 2010.

TORRES, Carlos Alberto. Reinventando Paulo Freire 40 anos depois. In: GADOTTI, Moacir (org.). 40 olhares sobre os 40 anos da pedagogia do oprimido. São Paulo: Editora e Livraria Instituto Paulo Freire, 2008. p. 12-13.

ZITKOSKI, Jaime José. A pedagogia freireana e suas bases filosóficas. In: SILVEIRA, Fabiane Tejada da; GHIGGI, Gomercindo; PITANO, Sandro de Castro (org.). Leituras de Paulo Freire: contribuições para o debate pedagógico contemporâneo. Pelotas: Seiva Publicações, 2007. p. 229-248. 